\title{
Morphological identification of Lucilia sericata, Lucilia cuprina and their hybrids (Diptera, Calliphoridae)
}

\author{
Kirstin A. Williams', Martin H. Villet ${ }^{2}$ \\ I Entomology Department, Durban Natural Science Museum, Durban, South Africa 2 Southern African \\ Forensic Entomology Research Laboratory, Department of Zoology and Entomology, Rhodes University, Gra- \\ hamstown, 6140 South Africa
}

Corresponding author: Kirstin A. Williams (Kirstin.Williams@durban.gov.za)

Academic editor: P. Cerretti | Received 8 April 2014 | Accepted 9 June 2014 | Published 25 June 2014

http://zoobank.org/A13A1EBC-6A83-4001-BC62-387C978E86A1

Citation: Williams KA, Villet MH (2014) Morphological identification of Lucilia sericata, Lucilia cuprina and their hybrids (Diptera, Calliphoridae). ZooKeys 420: 69-85. doi: 10.3897/zookeys.420.7645

\begin{abstract}
Hybrids of Lucilia sericata and Lucilia cuprina have been shown to exist in previous studies using molecular methods, but no study has shown explicitly that these hybrids can be identified morphologically. Published morphological characters used to identify L. sericata and L. cuprina were reviewed, and then scored and tested using specimens of both species and known hybrids. Ordination by multi-dimensional scaling indicated that the species were separable, and that hybrids resembled L. cuprina, whatever their origin. Discriminant function analysis of the characters successfully separated the specimens into three unambiguous groups - L. sericata, L. cuprina and hybrids. The hybrids were morphologically similar irrespective of whether they were from an ancient introgressed lineage or more modern. This is the first evidence that hybrids of these two species can be identified from their morphology. The usefulness of the morphological characters is also discussed and photographs of several characters are included to facilitate their assessment.
\end{abstract}

\section{Keywords}

Greenbottle blowflies, keys, morphology, discriminant analysis 


\section{Introduction}

The use of maggot debridement therapy (MDT) in South Africa has gained interest in the past decade (Williams et al. 2008, Du Plessis and Pretorius 2011). The identification of the maggots used for this therapy remains an issue, as most medical doctors are not adequately trained in entomology to correctly identify the flies (Williams et al. 2008, Tantawi et al. 2010). Lucilia sericata is the most commonly used species (Sherman et al. 2000) but it is often misidentified as L. cuprina. These two species are also used in forensic entomology (Louw and van der Linde 1993, Smith and Wall 1997, Anderson 2000, Oliva 2001, Clark et al. 2006, Day and Wallman 2006) and L. cuprina is the species most often responsible for sheep strike - myiasis of sheep by the maggots of this fly (Hepburn 1943, Ullyett 1945, Vogt and Woodburn 1979, Heath and Bishop 2006), but L. sericata is responsible for sheep strike in northern Europe where L. cuprina is absent (Rose and Wall 2011). Correct identification of these flies is thus vitally important for these three fields.

Several identification keys have been produced either specifically for $L$. sericata and L. cuprina, or for larger suites of Luciliinae or Calliphoridae that included these two species (Waterhouse and Paramonov 1950, Rognes 1980, 1994, Dear 1986, Holloway 1991, Wallman 2001, Whitworth 2006, 2010), but several of the diagnostic characters are sometimes omitted while others are included that are less reliable or difficult to observe. Although both species occur worldwide, some of the differences between the character suites in these studies may arise from considering samples from relatively limited geographical regions. The first aim of this study was to consider the value of the published characters based on a sample of specimens from across the world.

A complicating factor is the known and widespread existence of natural hybrids of these species (Stevens et al. 2002, Wallman et al. 2005, Tourle et al. 2009, DeBry et al. 2010, Williams and Villet 2013), which has been established by molecular methods. Tourle et al. (2009) developed a semi-quantitative morphological index for discriminating L. sericata and L. cuprina, and it provides some evidence that their hybrids might also be morphologically distinguishable. Specifically, genetically identified hybrid specimens tended to show more extreme index values than either parent species. The index incorporated six characters: femur colour; the numbers of paravertical setulae, scutellar hairs and humeral hairs; the pattern of the postoccular microtrichial pile; the length of the sternal hairs of males; and the position of the inner vertical seta of females. The second aim of this study was to determine if hybrid specimens can in fact be determined from their morphology.

\section{Materials and methods}

Twenty-four specimens of L. sericata, L. cuprina and their hybrids (Table 1) were chosen from specimens that had been sequenced for 28S, COI and Per genes (Williams and Villet 2013). These specimens were chosen to include geographically diverse locations 
Table I. Specimens previously identified by molecular markers (Williams and Villet 2013) used in the morphological analyses. (*hybrids).

\begin{tabular}{|c|c|c|}
\hline Species & Specimen & Country of origin \\
\hline Lucilia cuprina & C_EGT_01 & Egypt - Alexandria \\
\hline Lucilia cuprina & C_SA_BFN_01 & South Africa - Bloemfontein \\
\hline Lucilia cuprina & C_SA_BFN_02 & South Africa - Bloemfontein \\
\hline Lucilia cuprina & C_SA_BRT_01 & South Africa - Britstown \\
\hline Lucilia cuprina & C_SA_BRT_02 & South Africa - Britstown \\
\hline Lucilia cuprina & C_SA_DBN_12 & South Africa - Durban \\
\hline *Lucilia cuprina & C_SA_DBN_01 & South Africa - Durban \\
\hline *Lucilia cuprina & C_SA_DBN_06 & South Africa - Durban \\
\hline *Lucilia cuprina & C_SA_NEL_01 & South Africa - Nelspruit \\
\hline${ }^{*}$ Lucilia cuprina & C_SA_NEL_02 & South Africa - Nelspruit \\
\hline *Lucilia cuprina & C_THA_03 & Thailand - Chiang Mai \\
\hline *Lucilia cuprina & C_ZIM_02 & Zimbabwe - Matobos \\
\hline Lucilia sericata & S_FRC_02 & France - Montferrier-Sur-Lez \\
\hline Lucilia sericata & S_GER_01 & Germany - Kempen \\
\hline Lucilia sericata & S_JPN_04 & Japan - Iwate \\
\hline Lucilia sericata & S_NAM_01 & Namibia - Possession Island \\
\hline Lucilia sericata & S_NAM_02 & Namibia - Possession Island \\
\hline Lucilia sericata & S_SA_CT_01 & South Africa - Cape Town \\
\hline Lucilia sericata & S_SA_CT_05 & South Africa - Cape Town \\
\hline Lucilia sericata & S_SA_GHT_01 & South Africa - Grahamstown \\
\hline Lucilia sericata & S_SA_GHT_02 & South Africa - Grahamstown \\
\hline Lucilia sericata & S_SA_PTA_02 & South Africa - Pretoria \\
\hline Lucilia sericata & S_SA_WTB_02 & South Africa - Witbank \\
\hline Lucilia sericata & S_USA_01 & United States of America - Michigan \\
\hline
\end{tabular}

including Egypt, France, Germany, Japan, Namibia, South Africa, Thailand, the United States of America and Zimbabwe.

A total of 18 distinguishing morphological characteristics of adults of L. sericata and L. cuprina (Table 2) were obtained by reviewing several published sources (Waterhouse and Paramonov 1950, Rognes 1980, 1994, Dear 1986, Holloway 1991, Wallman 2001, Tourle et al. 2009, Whitworth 2006, 2010). Three characters referred to the male genitalia and three characters were specific to females. The males' characters could not be viewed without dissecting the specimens and because the majority of the genetically-identified specimens were female (Williams and Villet 2013), it was decided to include only females in the analysis. This reduced the number of characters to 15. Photographs of the specimens were taken using a Nikon D800 camera with a 105 $\mathrm{mm}$ lens and $124 \mathrm{~mm}$ extension to show several of the characters.

Each specimen was scored against the 15 characters (Table 2). Each character was then evaluated for its effectiveness in discriminating between the species and its practical value for identification, first univariately and qualitatively, and then multivariately and quantitatively using non-metric multi-dimensional scaling (MDS) in PAST3 


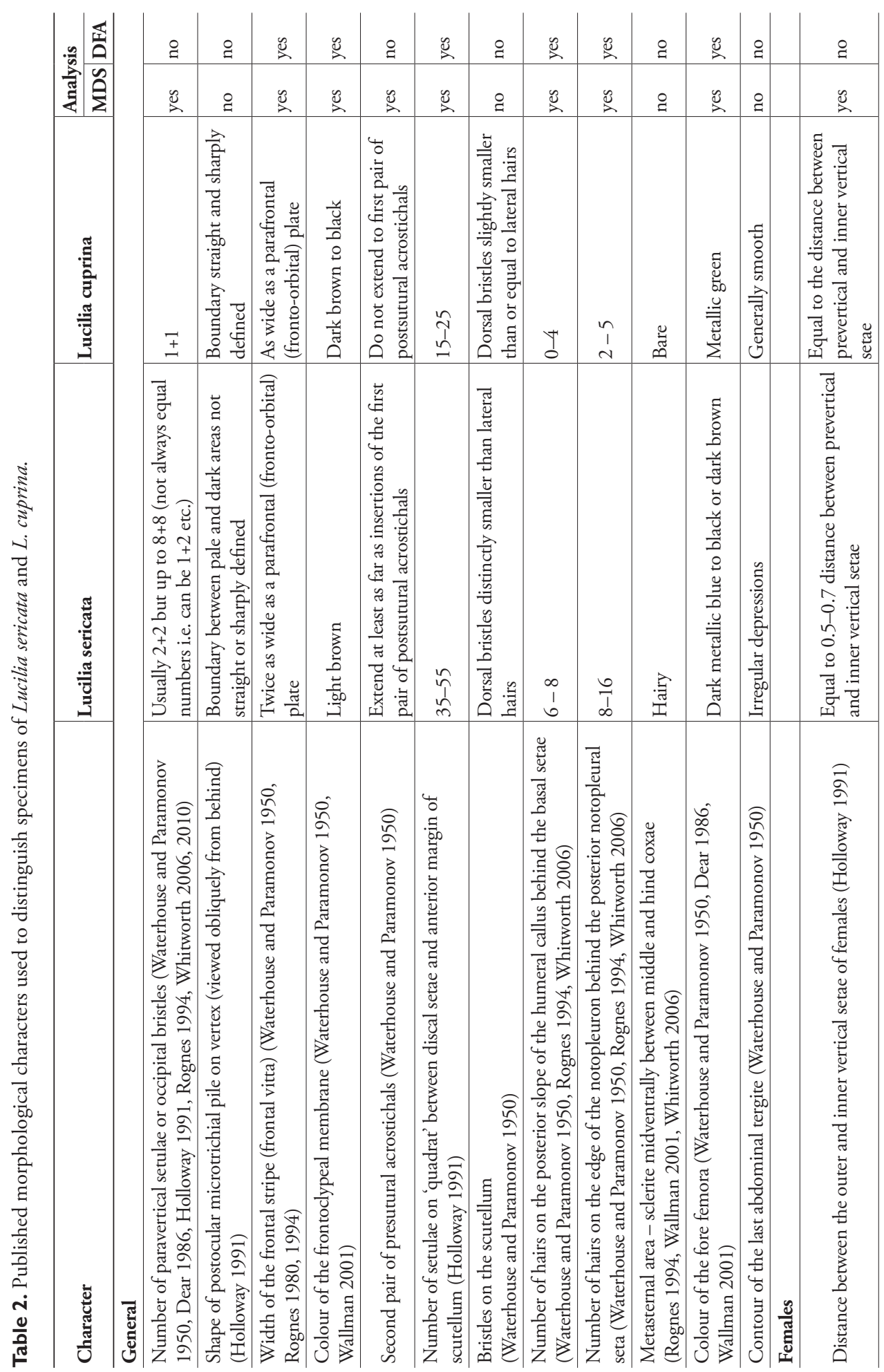




\begin{tabular}{|c|c|c|c|c|c|c|}
\hline & $\stackrel{8}{g}$ & $\stackrel{\mathscr{2}}{2}$ & & ̊ & ๑ & ̊ \\
\hline$\stackrel{\mathscr{2}}{\mathrm{E}}$ & 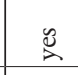 & 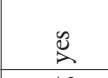 & & ๕ & G & \& \\
\hline 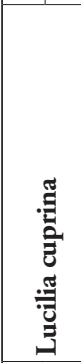 & 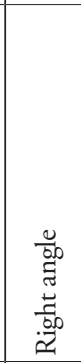 & 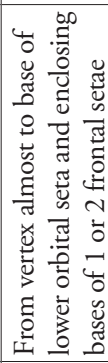 & & 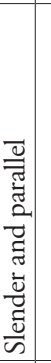 & 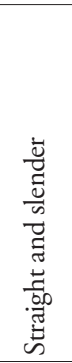 & 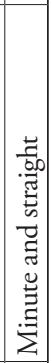 \\
\hline 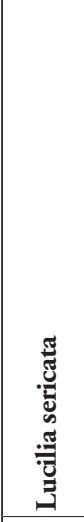 & 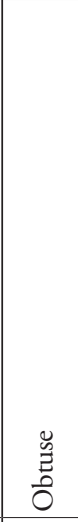 & 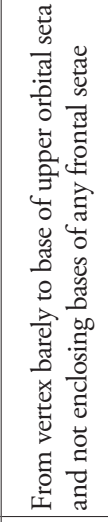 & & 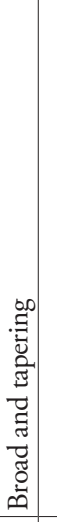 & 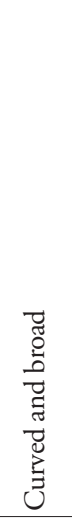 & 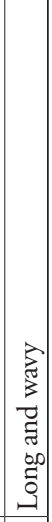 \\
\hline 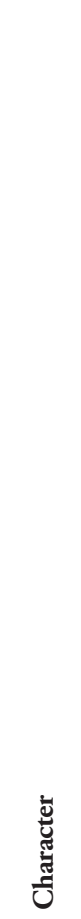 & 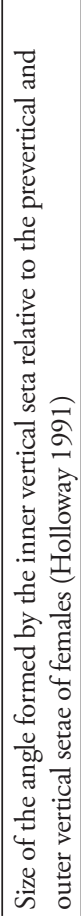 & 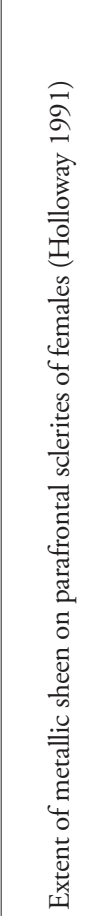 & $\frac{\ddot{y}}{\sum^{\frac{\pi}{2}}}$ & 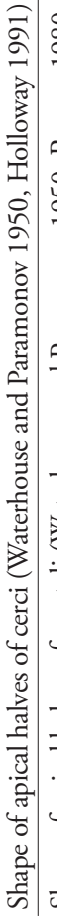 & 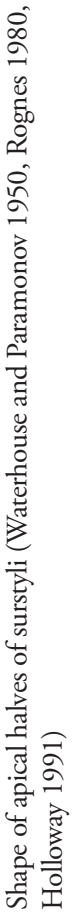 & 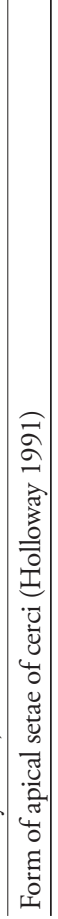 \\
\hline
\end{tabular}


(Hammer et al. 2001) using a Manhattan distance metric because of the mixed data forms in the character state matrix.

To explore the diagnosibility of the hybrids, a discriminant function analysis (DFA) was performed using PAST3 (Hammer et al. 2001) on the scored character matrix to determine which characters were most influential in identifying the species. Four of the 15 characters (shape of postocular microtrichial pile, hairiness of metasternal area, contour of the last abdominal tergite, bristles on the scutellum; Table 2) were either not easily visible or the hairs were broken or missing in at least half of the specimens and were therefore excluded from the DFA. Another four of the characters showed no variation within species and therefore had to be excluded from the DFA, which therefore included only seven characters (Table 2). The hybrid specimens were treated as a separate group in this analysis, but the introgressed and modern hybrids were not separated.

\section{Results}

\section{Univariate assessment of characters}

The number of paravertical setulae or occipital bristles (Table 2; Figure 1). This character was relatively consistent and reliable, but it is not easily viewed and scored if the specimens have been kept in ethanol. The hybrid specimens all keyed out as $L$. cuprina. This character was left out of the DFA analysis due to lack of variation within L. cuprina.

The shape of the postocular microtrichial pile on the vertex (Table 2) (Holloway 1991) is a difficult character to see when the specimens have been stored in ethanol because the microtrichia are not visible unless the specimen is dry, and even then the microtrichia sometimes appear to be absent. Due to the difficulty in viewing and scoring this character, it was eventually left out of all further analyses.

The relative positions of the three vertical setae (Table 2; Figure 1) that form a triangle on either side of the ocellar triangle in females (Holloway 1991) is a reliable character that consistently separated the two species. This character was excluded from the DFA because it did not show variation within taxa but was included in the MDS analysis. The hybrid specimens consistently keyed out as L. cuprina.

The angle formed by the three vertical setae (Table 2; Figure 1). This character is consistent and easily seen even if the setae have fallen out as they have sockets, which are easily visible. Due to lack of variation within species and the hybrids being identified as L. cuprina, this character was also excluded from the discriminant function analysis but it was included in the MDS analysis.

The extent of the metallic sheen on the parafrontal sclerites of females (Table 2 and Suppl. material 1; Figure 1). This character is easier to observe in dried specimens than ethanol-preserved specimens and there is some variation. The division between the two species is not absolute - there is some overlap within this character but it was not specific to the hybrids. It was included in both the DFA and MDS analyses. 


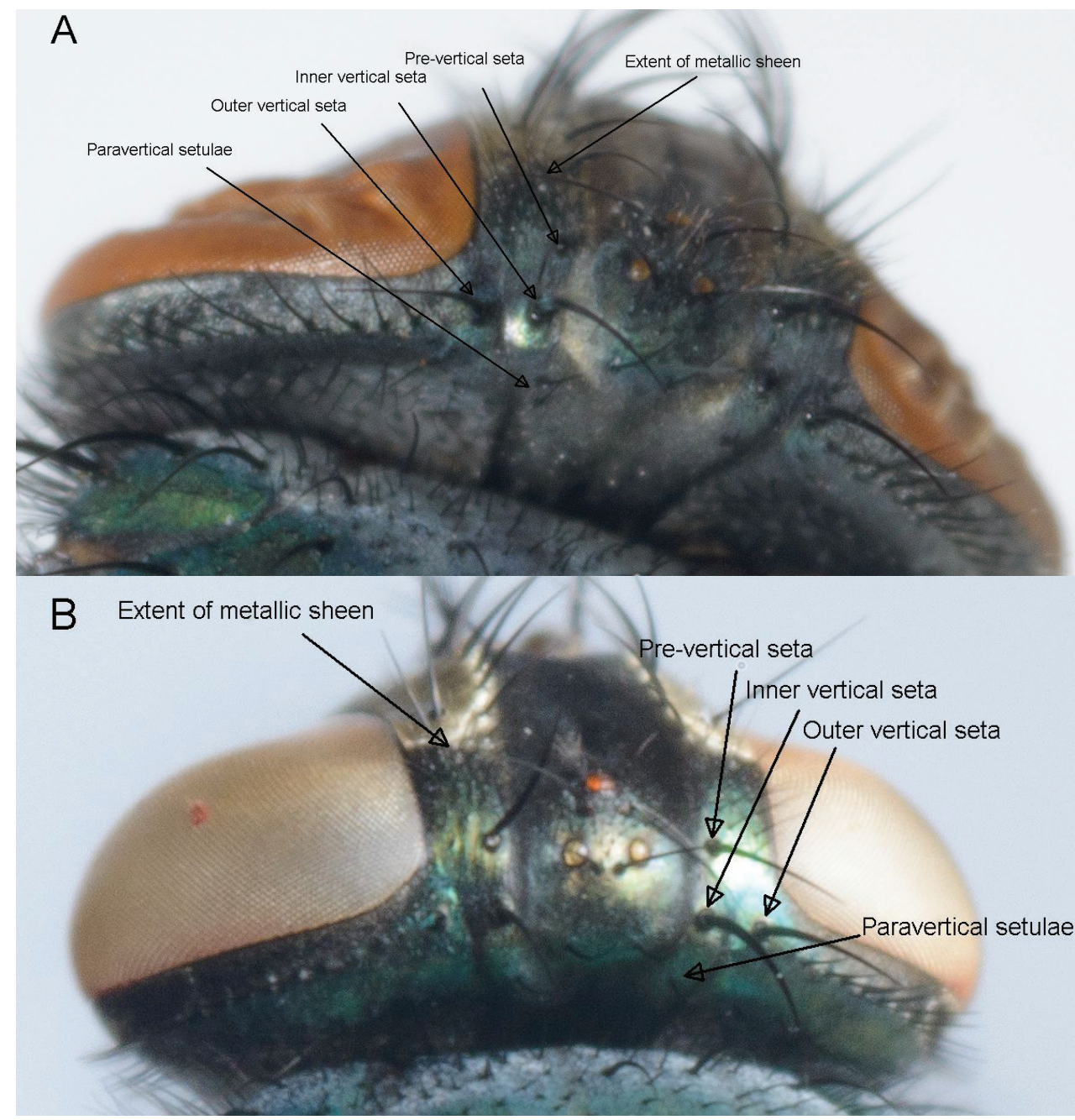

Figure I. Paravertical setulae, distance between the outer and inner vertical setae, the size of the angle at the inner vertical triangle and extent of metallic sheen on parafrontal sclerites. L. sericata $(\mathbf{A})$ and L. cuprina (B).

The relative width of the frontal stripe (frontal vitta) (Table 2 and Suppl. material 1; Figure 2). Waterhouse and Paramonov (1950) suggested that this character was more reliable in males than females. We found that the width varied from being equal to the parafrontal to being more than twice the width in both species. The hybrids were not distinguishable from L. cuprina. This character was included in the MDS and the DFA analyses.

The colour of the frontoclypeal membrane (Table 2 and Suppl. material 1; Figure 3). It was not always easily visible if the proboscis was not extended but it could usually be viewed by either manipulating the proboscis or viewing the specimen from 


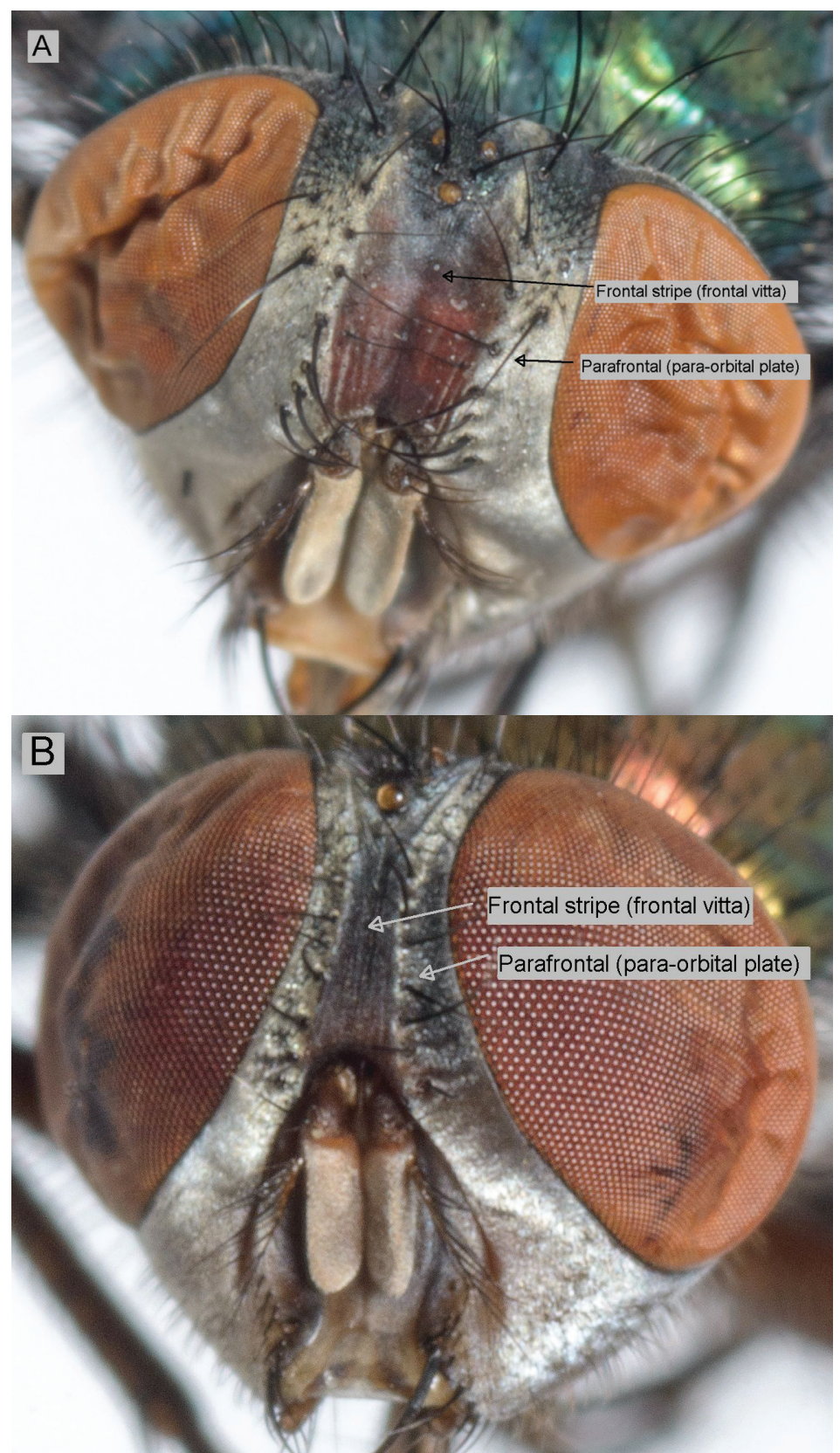

Figure 2. Frontal stripe - L. sericata $(\mathbf{A})$ and L. cuprina (B).

a lateral angle (Waterhouse and Paramonov 1950). The hybrid specimens were not distinct from L. sericata or L. cuprina.

The length of the second pair of presutural acrostichals (Table 2) is a character that is easier to see in well-preserved specimens (Waterhouse and Paramonov 1950). 

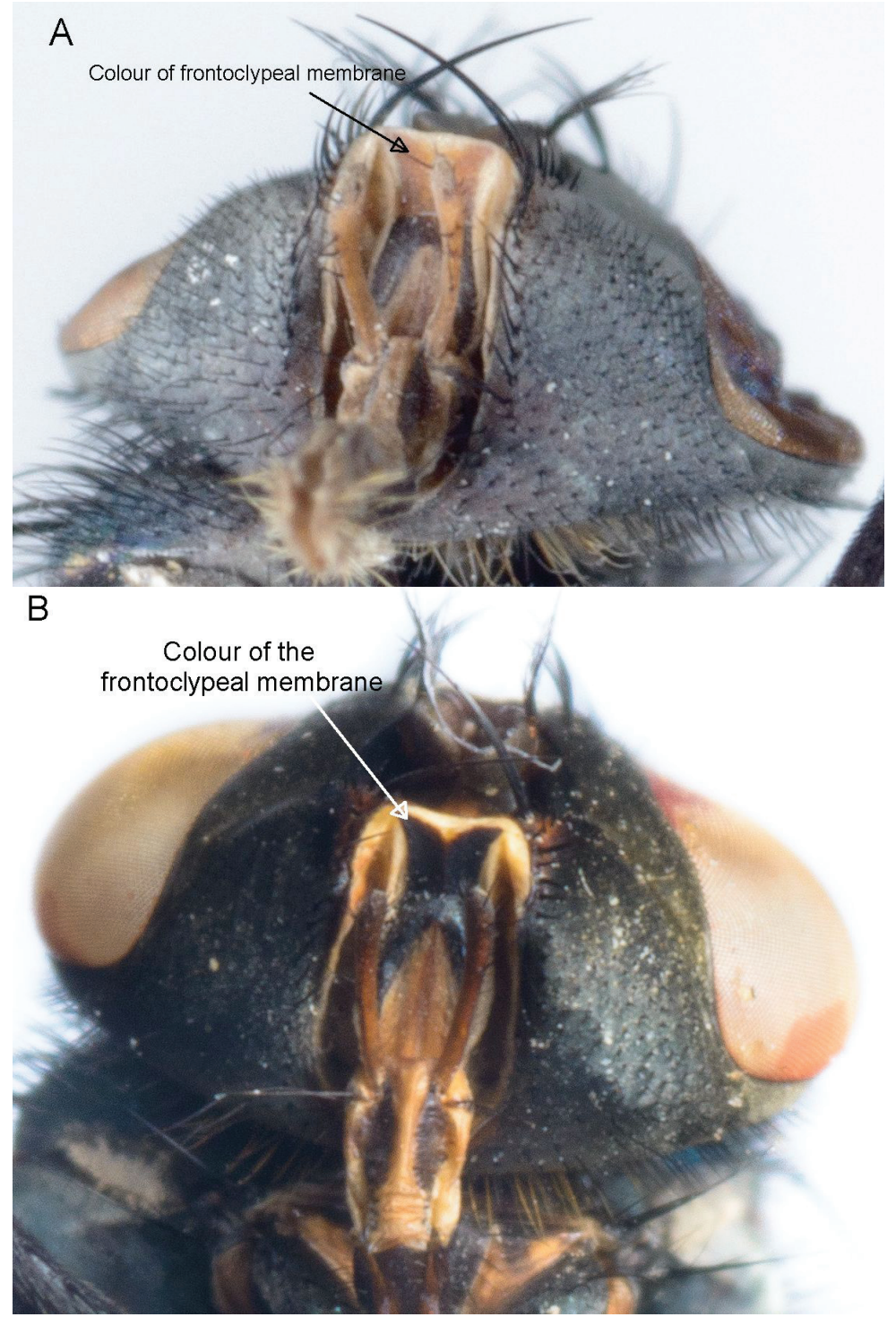

Figure 3. Colour of the frontoclypeal membrane. L. sericata (A) and L. cuprina (B).

This character is not scorable if the bristles are broken or have fallen out. It was left out of the analyses because it does not show any intraspecies variation.

The number of setae on the scutellum (Table 2 and Suppl. material 1; Figure 4) in the 'quadrat' demarcated by the discal setae and the anterior margin of the scutellum represents the axis in the discriminant analysis that separated L. sericata and L. cuprina (Holloway 1991). This character can be used even when the setae have fallen out because they have sockets that are visible and can be counted. There was overlap in the number of setae between the two species, but generally L. cuprina had obviously fewer 


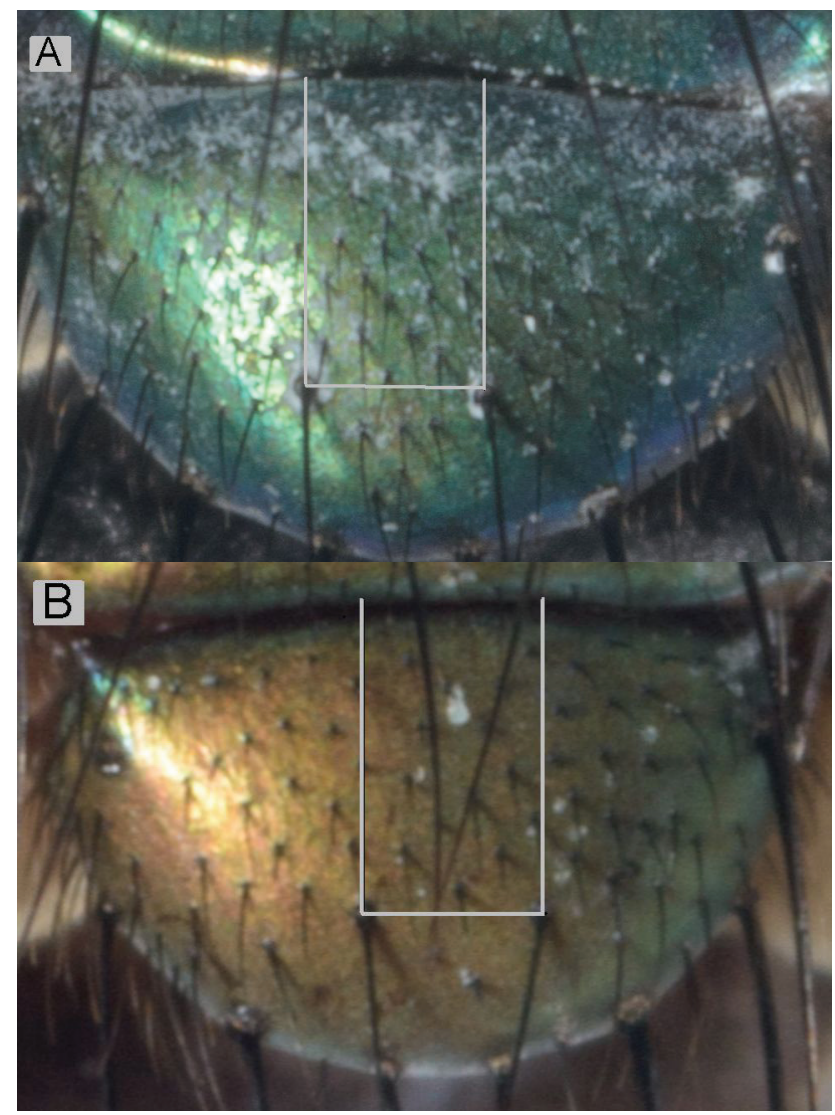

Figure 4. Number of setae on 'quadrat' between the anterior margin and discal setae on the scutellum. L. sericata (A) and L. cuprina (B).

setae. The number of setae in the hybrids was not obviously different from either of the pure species. This overlap may be as a result of the challenge of counting the setae as they are not in straight rows.

The length of the bristles on the scutellum (Table 2 and Suppl. material 1) describes the length of the hairs between the two anterior bristles on the lateral margin of the scutellum in relation to the length of the hairs on the dorsal surface of the scutellum (Waterhouse and Paramonov 1950). This character was not easy to use as the hairs were broken or had fallen out in half of the specimens and therefore it was left out of the analyses.

The hairiness of the posterior slope of the humeral callus (Table 2 and Suppl. material 1; Figure 5) behind the basal setae is a reliable character in separating $L$. sericata and L. cuprina even though there is variation within species in the number of hairs. The hybrids tended to have more hairs than the pure L. cuprina specimens, but there was still overlap in the numbers of hairs between the hybrids and pure L. cuprina. 

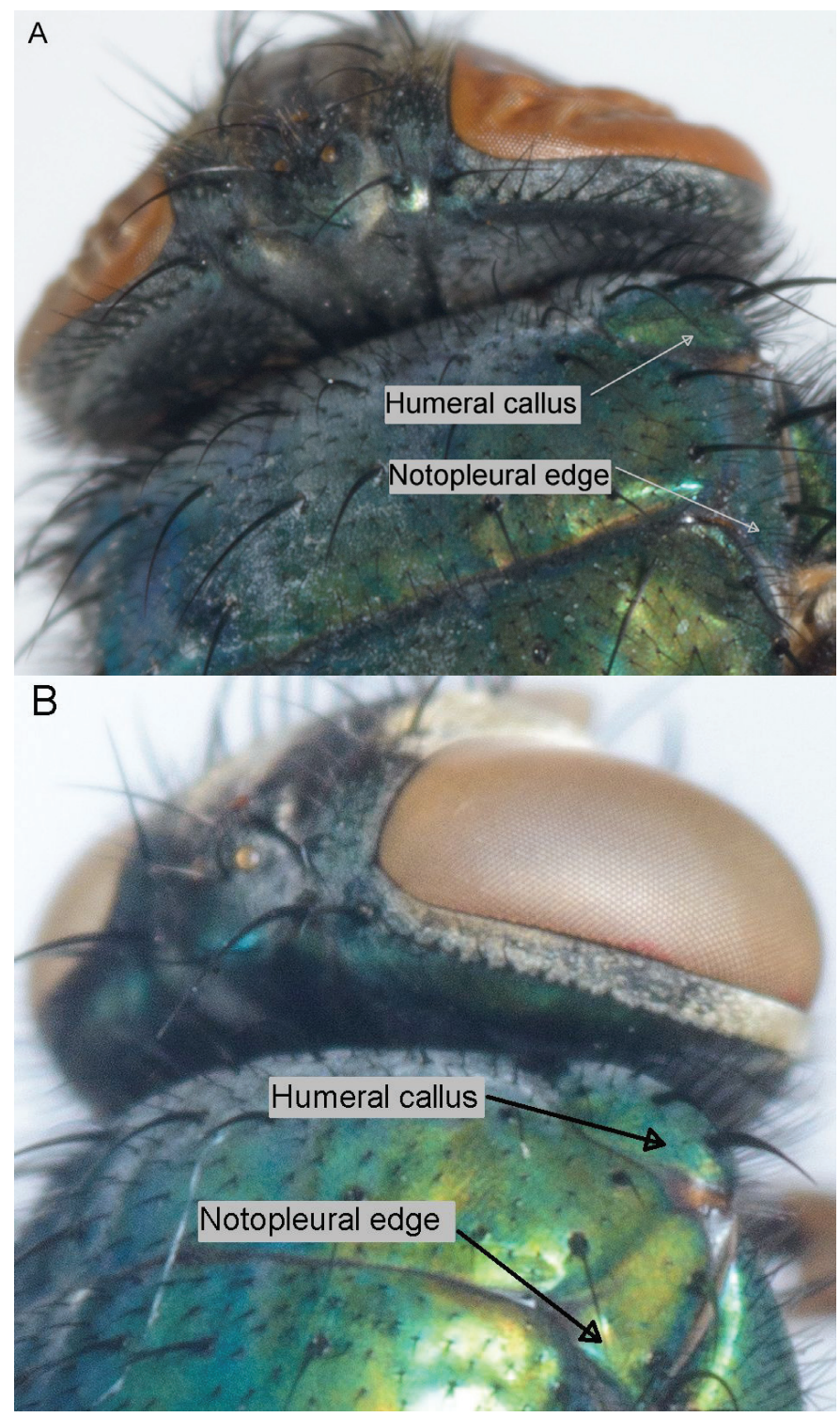

Figure 5. Posterior slope of the humeral callus behind the basal setae and the posterior edge of notopleuron behind the posterior notopleural seta. L. sericata $(\mathbf{A})$ and L. cuprina $(\mathbf{B})$.

The number of hairs on the edge of the notopleuron (Table 2 and Suppl. material 1; Figure 5). Both the hairs on the notopleuron and the humeral callus are relatively easy to observe although ethanol-preserved specimens need to be dried so that the small hairs are visible. It is another reliable character in separating $L$. sericata from L. cuprina despite variation in the number of hairs within species. The hybrids showed no discernable difference in numbers of hairs from L. cuprina. 


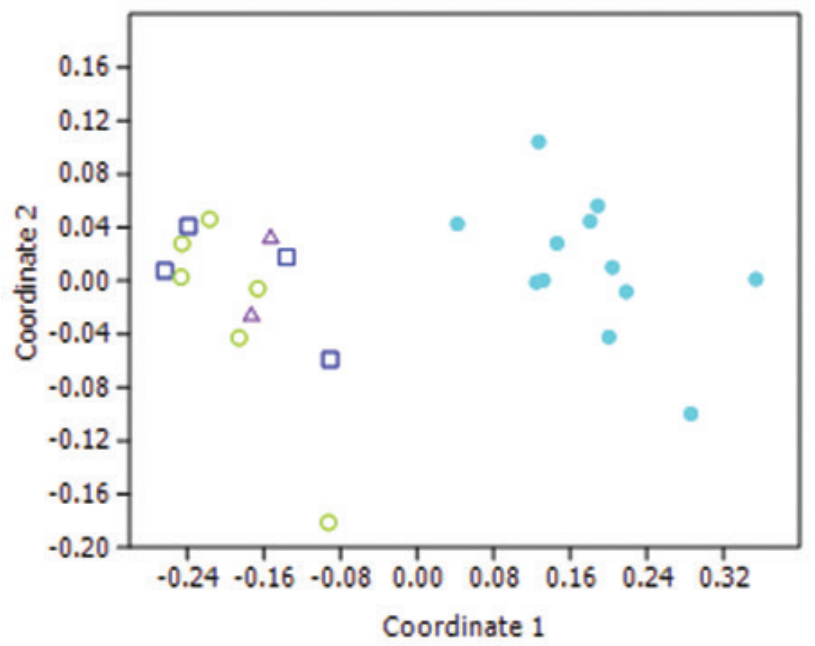

Figure 6. Non-metric Multi-Dimensional Scaling plot using a Manhattan distance metric using 11 characters. Light blue solid circles $=L$. sericata, Green open circles $=$ L. cuprina, dark blue squares $=$ introgressed hybrids, purple triangles $=$ modern hybrids.

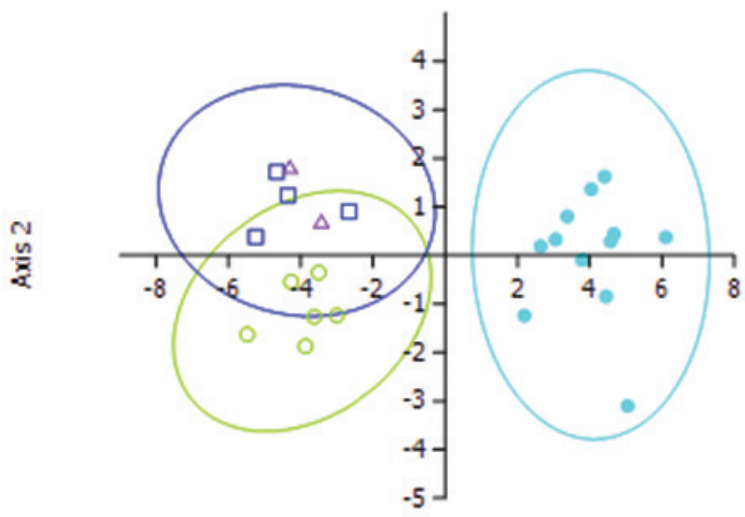

Axis 1

Figure 7. Ordination plot of the first two roots of the discriminant function analysis using seven characters. Ellipses represent 95\% confidence regions. Light blue solid circles $=$ L. sericata, Green open circles = L. cuprina, dark blue squares $=$ introgressed hybrids, purple triangles $=$ modern hybrids .

The hairs on the metasternal area (Table 2), which is the sclerite mid-ventrally between the middle and hind coxae, are exceedingly difficult to view if the legs are not set appropriately to facilitate this. . All of the specimens that we examined were preserved in ethanol and it was not easy to view the metasternal area and this character was therefore not analysed.

The colour of the fore femora (Table 2 and Suppl. material 1) has long been used as a character to identify L. sericata and L. cuprina (Ullyett 1945). It is a controversial 
Table 3. Eigen vectors and values for the first two roots of the discriminant function analysis.

\begin{tabular}{l|c|c}
\hline Character & Root $\mathbf{1}$ & Root 2 \\
\hline $\begin{array}{l}\text { Number of setulae on 'quadrat' demarcated by discal setae and anterior margin } \\
\text { of scutellum }\end{array}$ & $\mathbf{1 . 5 8 2 2}$ & 0.0324 \\
\hline Number of hairs on edge of notopleuron behind posterior notopleural seta & 0.5576 & 0.3300 \\
\hline Number of hairs on posterior slope of humeral callus behind basal setae & 0.4216 & $\mathbf{0 . 9 0 6 6}$ \\
\hline Colour of fore femora & 0.2591 & -0.2023 \\
\hline Relative width of frontal stripe (frontal vitta) & 0.1551 & 0.0104 \\
\hline Extent of metallic sheen on parafrontal sclerites of females & 0.0519 & -0.0697 \\
\hline Colour of frontoclypeal membrane & -0.1551 & -0.0104 \\
\hline Eigenvalue & 18.5560 & 0.7406 \\
\hline
\end{tabular}

character as it varies according to when the flies were killed, if the adults were fully matured and if the specimens were fouled or not during collection and thus is subject to personal interpretation. The hybrids keyed out as L. cuprina. Due to the variation in this character it was included in the DFA.

The contour of the last abdominal tergite (Table 2) is applicable only to dried specimens (Waterhouse and Paramonov 1950) as it relies on the hardness of the tergite. It was therefore not a character that could be used in our analyses as all our specimens were ethanol-preserved. It was excluded from the analyses and is probably unreliable even in dried specimens because it relies on the preservation of the specimen and how it is pinned, which affects the contour of the last abdominal tergite.

\section{Multivariate assessments of characters}

Superficially, the hybrid specimens were identified as L. cuprina when keyed out using any of the published keys. There were no obvious differences in the morphology of the hybrids. When the characters were analysed using MDS, the hybrid specimens were not separated from the L. cuprina specimens (Figure 6).

However, the ordination plot of the DFA (Figure 7) clearly shows three groups - L. sericata, L. cuprina and hybrids. The most influential characters were the number of setae on the scutellum (Root 1) and the number of hairs on the humeral callus (Root 2) (Table 3). It is not obvious in the morphology that there is a difference between the pure and hybrid strains, but statistically one can separate the hybrids from the pure L. cuprina specimens.

\section{Discussion}

\section{Assessment of characters}

Due to the greater number of female flies in the molecular study from which we chose our specimens, we did not include any males. Therefore the male genitalia characters 
are not discussed in detail. It is not possible to properly view the male genitalia without dissecting them and this is not ideal for non-entomologists such as medical doctors who are using these flies for MDT as one needs experience to dissect out the genitalia. It is possible to correctly identify these flies without using the male genitalia by using the other characters described in Table 2.

\section{Geographical variation}

Holloway (1991) suggested that the characters that she described were specifically for L. sericata and L. cuprina from New Zealand and that they might not apply to specimens from other parts of the world. This does not seem to be the case, as the flies examined in this study are from several different countries around the world (Table 1) and the characters described (excluding the male genitalia) were useful in identifying these two species and their hybrids.

\section{Identifying hybrids}

The DFA unambiguously separated the L. cuprina specimens from the hybrids and it was statistically significant. This was not noted in previous studies where hybrids were identified only through molecular techniques (Stevens et al. 2002, Wallman et al. 2005, Tourle et al. 2009, DeBry et al. 2010, Williams and Villet 2013). Examination of the number of hairs on the scutellum, humeral callus and notopleuron show a consistent difference that separates these groups. The first two characters were included in the morphological index designed by Tourle et al (2009), which explains the trend found in their results.

The introgressed and modern hybrids were not separated in the DFA ordination plot (Fig. 6).

\section{Conclusion}

Introgressed and modern hybrids of $L$. sericata and $L$. cuprina can be statistically recognized using the characters described in this paper.

Four of the characters were consistently successful at separating $L$. sericata and L. cuprina (number of paravertical setulae or occipital bristles, distance between the outer and inner vertical setae of females, size of the angle at the inner vertical in triangle joining pre-, outer and inner vertical setae of females, second pair of presutural acrostichals) with little variation within the characters. The number of setae on the scutellum and the number of hairs on the humeral callus and notopleuron are also useful characters although they did show variation within species. It is advisable to use a combination of several characters to identify these two species as no single character was sufficient to separate $L$. sericata and $L$. cuprina. 


\section{Acknowledgments}

We thank Georg Goergen, Ashley Kirk-Spriggs, Nicky Lunt, Mervyn Mansell, Hideharu Numata, Cameron Richards, Kiyoshi Saigusa, Kabkaew Sukontason, Tarek Tantawi and Robyn Tourle for providing us with specimens, Emil von Maltitz for taking photographs. Funding was provided by the National Research Foundation (NRF) of South Africa. Any opinion, findings and conclusions or recommendations expressed in this material are those of the authors and do not necessarily reflect the views of the National Research Foundation.

\section{References}

Anderson GS (2000) Minimum and maximum development rates of some forensically important Calliphoridae (Diptera). Journal of Forensic Sciences 45: 824-832.

Clark K, Evans L, Wall R (2006) Growth rates of the blowfly, Lucilia sericata, on different body tissues. Forensic Science International 156: 145-149. doi: 10.1016/j.forsciint.2004.12.025

Day DM, Wallman JF (2006) Influence of substrate tissue type on larval growth in Calliphora augur and Lucilia cuprina (Diptera: Calliphoridae). Journal of Forensic Sciences 51: 657-663. doi: 10.1111/j.1556-4029.2006.00127.x

DeBry R, Timm AE, Dahlem GA, Stamper T (2010) mtDNA-based identification of Lucilia cuprina (Wiedemann) and Lucilia sericata (Meigen) (Diptera: Calliphoridae) in the continental United States. Forensic Science International 202: 102-109. doi: 10.1016/j. forsciint.2010.04.038

Dear JP (1986) Calliphoridae (Insecta: Diptera). Fauna of New Zealand 8: 1-86.

Du Plessis HJC, Pretorius JP (2011) The utilisation of maggot debridement therapy in Pretoria, South Africa. Wound Healing Southern Africa 4: 80-83.

Hammer $\varnothing$, Harper DAT, Ryan PD (2001) PAST: Paleontological Statistics Software Package for Education and Data Analysis. Palaeontologia Electronica 4: 9 pp.

Heath ACG, Bishop DM (2006) Flystrike in New Zealand: An overview based on a 16-year study, following the introduction and dispersal of the Australian sheep blowfly, Lucilia cuprina Wiedemann (Diptera: Calliphoridae). Veterinary Parasitology 137: 333-344. doi: 10.1016/j.vetpar.2006.01.006

Hepburn GA (1943) Sheep blowfly research I - A survey of maggot collections from live sheep and a note on the trapping of blowflies. Onderstepoort Journal of Veterinary Science and Animal Industry 18: 13-18.

Holloway BA (1991) Morphological characters to identify adult Lucilia sericata (Meigen, 1826) and L. cuprina (Wiedemann, 1830) (Diptera: Calliphoridae). New Zealand Journal of Zoology 18: 415-420. doi: 10.1080/03014223.1991.10422847

Louw S v.d.M, van der Linde TC (1993) Insects frequenting decomposing corpses in central South Africa. African Entomology 1: 265-269.

Oliva A (2001) Insects of forensic significance in Argentina. Forensic Science International 120: 145-154. doi: 10.1016/S0379-0738(01)00423-6 
Rognes K (1980) The blow-fly genus Lucilia Robineau-Desvoidy (Diptera, Calliphoridae) in Norway. Fauna Norvegica Series B 27: 39-52.

Rognes K (1994) First record of the sheep greenbottle fly Lucilia cuprina (Wiedemann, 1830) from Europe (Diptera: Calliphoridae) with additional Spanish records of Calliphoridae, Muscidae and Sarcophagidae. Eos 69: 41-44.

Rose H, Wall R (2011) Modelling the impact of climate change on spatial patterns of disease risk: Sheep blowfly strike by Lucilia sericata in Great Britain. International Journal of Parasitology 41: 739-746. doi: 10.1016/j.ijpara.2011.01.012

Sherman RA, Hall MJR, Thomas S (2000) Medicinal maggots: an ancient remedy for some contemporary afflictions. Annual Review of Entomology 45: 55-81. doi: 10.1146/annurev.ento.45.1.55

Smith KE, Wall R (1997) The use of carrion as breeding site by the blowfly Lucilia sericata and other Calliphoridae. Medical and Veterinary Entomology 11: 38-44. doi: 10.1111/ j.1365-2915.1997.tb00287.x

Stevens JR, Wall R, Wells JD (2002) Paraphyly in Hawaiian hybrid blowfly populations and the evolutionary history of anthropophilic species. Insect Molecular Biology 11: 141-148. doi: 10.1046/j.1365-2583.2002.00318.x

Tantawi TI, Williams KA, Villet MH (2010) An Accidental but safe and effective use of Lucilia cuprina (Diptera: Calliphoridae) in maggot debridement therapy in Alexandria, Egypt. Journal of Medical Entomology 47: 491-494. doi: 10.1603/ME09183

Tourle RA, Downie DA, Villet MH (2009) A morphological and molecular comparison of Lucilia cuprina and L. sericata (Diptera: Calliphoridae) in South Africa. Medical and Veterinary Entomology 23: 6-14. doi: 10.1111/j.1365-2915.2008.00765.x

Ullyett GC (1945) Species of Lucilia attacking sheep in South Africa. Nature 155: 636-637. doi: $10.1038 / 155636 b 0$

Vogt WG, Woodburn TL (1979) Ecology, distribution and importance of sheep myiasis flies in Australia. National Symposium of the Sheep Blowfly and Flystrike in Sheep. New South Wales Department of Agriculture Sydney, Australia, 23-32.

Wallman JF (2001) A key to the adults of species of blowflies in southern Australia known or suspected to bred in carrion [corrigendum in Medical and Veterinary Entomology 16, 223]. Medical and Veterinary Entomology 15: 433-437. doi: 10.1046/j.0269283x.2001.00331.x

Wallman JF, Leys R, Hogendoorn K (2005) Molecular systematics of Australian carrion-breeding blowflies (Diptera: Calliphoridae) based on mitochondrial DNA. Invertebrate Systematics 19: 1-15. doi: 10.1071/IS04023

Waterhouse DF, Paramonov SJ (1950) The status of the two species of Lucilia (Diptera, Calliphoridae) attacking sheep in Australia. Australian Journal of Scientific Research 3: 310-336.

Whitworth T (2006) Keys to the genera and species of blow flies (Diptera: Calliphoridae) of America north of Mexico. Proceedings of the Entomological Society of Washington 108: 689-725.

Whitworth T (2010) Keys to the genera and species of blow flies (Diptera: Calliphoridae) of the West Indies and description of a new species of Lucilia Robineau-Desvoidy. Zootaxa 2663: 1-35. 
Williams KA, Cronje FJ, Avenant L, Villet MH (2008) Identifying flies used for maggot debridement therapy. South African Medical Journal 98: 196-197.

Williams KA, Villet MH (2013) Ancient and modern hybridization between Lucilia sericata and L. cuprina (Diptera: Calliphoridae). European Journal of Entomology 110: 187-196. doi: $10.14411 /$ je.2013.029

\section{Supplementary material I}

\section{Character-taxon matrix}

Kirstin A. Williams, Martin H. Villet

Data type: Species data

Explanation note: Character-taxon matrix used in the MDS and DFA analyses

Copyright notice: This dataset is made available under the Open Database License (http://opendatacommons.org/licenses/odbl/1.0/). The Open Database License $(\mathrm{ODbL})$ is a license agreement intended to allow users to freely share, modify, and use this Dataset while maintaining this same freedom for others, provided that the original source and author(s) are credited.

Link: doi: 10.3897/zookeys.420.7645.app1 